Volume 7

Issue 3 May

Article 6

May 1980

\title{
Veterans' Medical Care: The Politics of an American Government Health Service
}

Judith Lasker

Bucknell University

Follow this and additional works at: https://scholarworks.wmich.edu/jssw

Part of the Health Policy Commons, and the Social Work Commons

\section{Recommended Citation}

Lasker, Judith (1980) "Veterans' Medical Care: The Politics of an American Government Health Service," The Journal of Sociology \& Social Welfare: Vol. 7 : Iss. 3 , Article 6.

Available at: https://scholarworks.wmich.edu/jssw/vol7/iss3/6 


\title{
VETERANS' MEDICAL CARE; \\ THE POLITICS OF AN AMERICAN GOVERNMENT HEALTH SERVICE ${ }^{1}$
}

\author{
Judith Lasker \\ Bucknell University
}

\begin{abstract}
The history of veterans' benefits and services in the United States is reviewed; it demonstrates their responsiveness to dominant political, economic, military and medical interests. The ideological position that social services must be "deserved" is also seen to be an important influence on the V.A. system. The consequent inaccessibility of V.A. medical care to most veterans and almost a11 non-veterans raises questions about the appropriateness of the V.A. system as a model for national health care.
\end{abstract}

The vast and ever-increasing literature on medical care in the United States all but ignores a major component of the national medical system--the medical services and institutions of the Veterans Administration. Although the V.A. has the "largest medical-care delivery system in the United States" (National Academy of Sciences, 1977: 1), it is rare to find it even mentioned in discussions of national health policies. However, when it is mentioned in the literature, the V.A. is often discussed as a model for a potential national health system (Lipsky et al, 1976; Sapolsky, 1977; Chase, 1977). Since, despite criticisms of its quality and relevance (National Academy of Sciences, 1977; Starr, 1973), the V.A. is likely to continue to be an important segment of American health care in any type of future system, it is essential to examine the model carefully. This paper reviews avallable literature, the history of veterans' medical services, and recently collected utilization data in order to analyze the principles underlying the creation and continued growth of the V.A. medical system. One must examine the forces which have influenced this set of institutions if one wants to consider the possibilities for a system of national health care in the United States.

One can only conclude from the paucity of literature that the V.A. medical system is considered an aberration by most students of American health care (if it is considered at all)--a federally-run national health service in a nation presumably dedicated to free enterprise

1. I would like to thank Bucknell University for a grant received to carry out this research. Thanks also to Gregory Gaertner, Allen Imershein, Florence Katz, Arnold Lasker, Miriam Lasker, John Kendrick, Jean Potuchek, Matthew Silberman, Barry Siegel, Martha Verbrugge, Albert Wessen and the V.A. library staff for their helpful comments and 
medicine. This paper will present the proposition that the V.A. medical system is not at all an aberration. Rather, I suggest that it is very similar to other health and social services in the United States. It consists of a set of resources whose distribution and administration have been subject to the priorities of dominant interests in the society. Military, political, economic, and medical elites have all participated in shaping medical care for veterans. Although their efforts have produced ever-improving and expanding services for millions of people, their interests in the V.A. system go beyond the goal of caring for veterans' medical problems. The other priorities may in fact conflict with or detract from the ideal of comprehensive, accessible, and high quality health care. It is these other goals which will be considered in this paper.

It will be necessary first to discuss this view of social services as societal resources allocated to serve goals other than those of meeting the needs of clients. Secondly, the history of veterans' services will be examined as an example of this phenomenon, and the impact of various interests on that history will be analyzed. An additional factor which affects V.A. medicine and is also signifcant in other social services is the ideological position that some potential clients are more deserving of services than others. The specific characteristics of the hierarchy of eligibility are also related to non-medical priorities. In the last section, the effect these issues have on the ability of the V.A. to meet the needs of its client population will be considered. The purpose here is to analyze the factors which result in the inequitable distribution of national social welfare resources. A national health system which resembles the V.A. would potentially also be subject to these same inequalities.

\section{The Politics of Social Services}

A number of authors over the last few years have examined health and social services in the U.S. and have pointed out that they serve the economic and political interests of dominant groups in the society. Foremost among these analysts has been Vicente Navarro $(1976,1977 a)$, who has demonstrated that ownership and/or control of medical services by the upper-class have produced a system which meets the needs of this small minority more than those of the majority of the population. Krause examines the process by which health programs are subordinated to the goals of power and profit and how this is justified by the dominant capitalist idealogy. He asserts that "...health care is simply one type of housekeeping function which a capitalist state needs to keep the wheels of industry rolling,... no understanding of the health service system is possibje without looking outside of it to the wider political economy" (1977: 154). 
Studies of medical services in other societies have also revealed underlying interests which produce systems of ten unresponsive to the health problems of the population. For instance, Field's (1957) study of medical services in the Soviet Union during the Stalinist era of heavy industrialization showed the role of physicians in promoting economic growth by limiting the number of sick days available to workers. An analysis of health care in the Ivory Coast reveals the continuous use of medical resources, both during colonial rule and after independence, to promote economic growth and political stability (Lasker, 1977). An increasing number of studies on national health systems support this viewpoint (Navarro, 1977b).

When the state is directly involved in the planning and direction of health care services, as it is in most nations other than the United States, the impact of these other interests is most visible. Yet the same analysis can also be applied in the American context. Waitzkin and Navarro both note that the American government uses medical resources to reduce popular dissent, to provide profit for private industry, and to reinforce "dominant frameworks in scientific and clinical medicine that are consistent with the capitalist economic system" (Waitzkin, 1978: 36).

The state's support of economic and political goals through the distribution of medical resources is one aspect of its activities in the broader area of social welfare services. A number of scholars have pointed out the many ways in which American welfare policies respond to the dominant capitalist interests by promoting stability, maintaining a reserve of surplus labor, funding private enterprise (for instance, through housing programs) and reinforcing values of individualism (by stigmatizing recipients and eliminating from the rolls any who might be considered 'undeserving'). These priorities have shaped policy much more than any assessment of the needs of the nation's poor. (Piven and Cloward, 1971; Galper, 1975).

The V.A. medical care system offers an important case to illustrate the applicability of this analysis to medical care in the United States. It reflects both direct state involvement and the influence of the institutions and models of private medicine. It is funded and administered by the federal government but is closely tied to medical schools and the prevailing patterns of personnel training and hierarchy. Studying the history of the V.A. illuminates the significance of political, military, economic and organized medical interests in determining the characteristics of V.A. medical care. 


\section{V.A. Medical Care - Historical Overview ${ }^{1}$}

Medical care was first made available to disabled veterans in the United States with the establishment of the Soldiers' Home, the Naval Home, and the National Homes for Disabled Volunteer Soldiers following the Civil War. Except for the men admitted to these few institutions, no other medical care was provided for veterans until World War I, when Public Health Service hospitals or private hospitals under contract with the Bureau of War Risk Insurance cared for the war-injured.

By 1920 , fifty government hospitals were treating disabled soldiers and veterans, and Congress allocated funds for the construction of more hospitals. A Veterans' Bureau, created in 1921 to consolidate insurance and medical functions, took over the administration of the Public Health Service Hospitals which were serving veterans. In 1930, the Veterans Administration replaced the Veterans Bureau and incorporated the National Homes and the Bureau of Pensions. Since 1930, the V.A. system has continued to grow. It now operates 172 hospitals, 104 nursing homes and domiciliaries, and 220 outpatient clinics, employs 181,000 people, and has a budget for 1980 of $\$ 5.6$ billion (Wehr, 1979a).

The growth of V.A. medical services has continued both in wartime and in peacetime, due to a different set of forces at work in each situation. During every war in this century, Congress has allocated increased funds for the care of the wounded. Each period of mobilization produced additional veterans and added to the numbers of the disabled. As a result, facilities were expanded and new ones built to accommodate the demand.

The number of disabled patients diminished, however, within a few years after each war, leaving the problem of unused hospital beds. The recent war having strengthened the V.A. structures and contributed to the ranks of veterans' organizations, political pressures were brought to bear on Congress to loosen eligibility requirements in order to increase admissions rather than cut back on facilities. By the time the next war started, the V.A. hospitals were again close to capacity, and Congress again allocated funds for additional facilities to accommodate the increased number of veterans and wounded soldiers. The result of this continual expansion in eligibility and beds is that, at present, only $17 \%$ of patients in V.A. hospitals are being treated for service-connected disabilities; most of the others are admitted on the basis of other criteria such as economic need (Cleland, 1979).

1. Unless otherwise indicated, historical information on veterans medical care in this and other sections was drawn from two sources: Adkins, 1967, and Weber and Schmeckebier, 1934. 
Despite the important influence of the V.A. and its employees, the veterans' organizations, and supporters in Congress, veterans' medical services have also come under attack from a wide variety of sources. Increase in access to these services for the non-disabled has been opposed by private medicine as unfairly competitive. The quality of care provided in veterans' institutions has been continuously challenged by journalists and scholars. Most recently there has been considerable debate within government over the possibility of merger between V.A. and private medical care. Proponents of this merger point to the fact that only in medical care does the V.A. provide direct services rather than helping the veterans to purchase from the private market place, as it does in education and housing. The possibility of national health insurance as well as criticisms of quality, cost, duplication of services, and difficulty of access have all fueled the controversy over the future of veterans' medical care. Nevertheless, the V.A. medical system has continued to grow and will certainly persist in the foreseeable future (cf. Lindsay, 1975).

III. Influences on V.A. Health Care

1) Political Interests

The fact that political influence of different groups has played an important role in the development of the V.A. system is hardly surprising, since it is a creature of the legislative process. It is interesting, however, to examine the role of political influence in the expansion of facilities and benefits. The veterans' organizations (American Legion, Disabled American Veterans, Veterans of Foreign Wars, etc.) are the most intensely involved in influencing the political process, and veterans in Congress play a strategic role in the passage of legislation regarding the V.A.

The importance of political pressure from veterans is probably as old as the existence of benefits. In the fifteenth century, for example, when standing armies developed to serve feudal lords, disabled soldiers were cut off from community support, and they organized to demand redress. This pressure led to the formulation of a variety of pension plans and domiciliary homes. These plans were limited and mostly unsuccessful, but during the sixteenth and seventeenth centuries, the number of veterans' homes and assistance plans increased in Europe, and these were adopted in part by the American colonies.

Active organizing of veterans in the United States dates to the turn of this century. The United Spanish War Veterans was founded in 1898; Veterans of Foreign Wars was established in 1913. Both exerted pressure on Congress to expand benefits, and partly as a result of this pressure, both pension and medical benefits were greatly liberalized following World War $\mathbf{I}$. 
The effect of organized protest is also seen whenever efforts are made to cut back on benefits. In 1933 Congress passed a bill, proposed by President Roosevelt in response to Depression conditions, which drastically reduced pensions and services for veterans. After massive protest and despite a presidential veto, Congress reversed itself in 1934. A similar result occurred in 1965 when a new V.A. administrator ordered the closing of some outmoded and underutilized hospitals and the building of new ones in other areas. Veterans' organizations,V.A. employees and Congressmen from the affected districts opposed the plan, resulting in a review and modification.

More recently, a report by the National Academy of Sciences on "Health Care for American Veterans", commissioned by Congress, created a great furor by proposing the gradual integration of V.A. medical facilities with the private medical sector, suggesting that a separate system is unnecessary. Members of Congress interested in veteran' affairs, many of whom are themselves veterans of military service, responded angrily by attacking the NAS study group and initiating an audit of its books by the General Accounting office (Science, 1978).

According to an editorial in the New England Journal of Medicine (1978) commenting on the report's reception, "...the V.A. medical care system is a sacred cow. The whole subject is so loaded with political emotion and vested interests that rational public discourse is hardly possible." An editor of Science responded similarly: "The V.A., of course, has a unique clientele and a history of special treatment by Congress. There are roughly 28 million veterans who, with their families, constitute a potentially formidable voting bloc. Veterans' interests are championed by veterans' organizations which form a highly effective single interest lobby." In addition to these groups, the many families supported by jobs in the V.A. hospitals also have an interest in their continuation. The editorial concludes that the NAS study group had "triggered a powerful, protective, conditioned reflex" (Science, 1978).

The organized pressure of interested groups combined with the military service history of many powerful members of Congress has resulted in the continued expansion of services and benefits. For instance, recent legislation created counseling programs for Vietnamera veterans, preventive health services for veterans with serviceconnected disabilities, and expanded medical services for dependents, and increased outpatient dental care. When two fiscally conservative senators challenged these expenditures in committee and succeeded in cutting the amount of money allocated in the bill by one-third, their action was quickly reversed by the Congress. The combined efforts of veterans' groups, the V.A. staff, and veterans in Congress has resulted in continual growth of such new programs and expansion of eligibility for existing programs (Wehr, 1979a, 1979b, 1979c; Crosby, 1979). Political influence has also played an important part in 
the location of facilities; a number of cities are the sites of V.A. hospitals because they were the home towns of an American president or of an influential member of Congress (Sapolsky, 1977: 373-4).

Despite evidence of their continued impact on legislation, leaders of veterans' organizations worry about that they consider to be a decline in their political influence. They point in particular to efforts by President Carter and the Office of Management and Budget to cut back on medical personnel, facilities, and benefits in order to save money. The decreasing proportion of members of Congress with military service histories and the fading of public support for veterans, especially after Vietnam, have made the V.A. increasingly vulnerable to the actions of budget-conscious officials (Estill, 1979; Wehr, 1979d). According to the Twentieth Century Fund Task Force on Policies toward Veterans, the strength of the veterans' organizations has decreased steadily since the 1950's because of the lack of participation of younger veterans. Nevertheless, "Theirs is virtually the only point of view ever expressed before the congressional veterans committees...no countervailing political force has yet managed to dispute effectively the view of the veterans' organizations". The report concludes that future Congressional response to organized veterans' demands is "hard to predict" (Taussig, 1974: 57-9). The dependence of medical services on political interests has up until now usually worked to the advantage of the V.A. system as a whole, but it may also ultimately lead to the curtailment of those services.

\section{2) Military Interests}

Educational, financial, and employment benefits have all been used in the U.S., as elsewhere, to induce military enlistments. Historically, one major incentive for men to become soldiers has been the reward of plunder and some times even parts of the conquered territories. Other kinds of state-sponsored rewards also served as incentives to fight. The ancient Greeks freed helots who offered distinguished service and also fed and pensioned disabled soldiers. An English law passed in 1592 to provide "for the Reliefe of Souldiours" offered pensions to the disabled "to the end that they may reap the fruit of their good deservings, and that others may be encouraged to perform the like endeavors." This latter intent was reflected in legislation passed in the American colonies. New Hampshire in 1718 legislated medical care for disabled veterans "for the better encouragement of soldiers to adventure their persons against the enemy." George Washington, after initially opposing service pensions for officers during the Revolutionary War, later changed his mind when many officers deserted the ranks, and he wrote to the Continental Congress asking for pensions in order to be able to keep enough officers to win the war. 
When the first peacetime conscription was established by Congress in 1940, the bill included a variety of benefits for veterans, intended in part to reduce opposition to the draft. Men were reluctant to give up their jobs during a time of high unemployment, and the promise of government assistance after their release from service was offered as an incentive to assure the success of conscription. The G.I. Bill of 1944 was built upon these earlier provisions (O1son, 1974).

\section{3) Economic Interests}

Some of the efforts made to encourage enlistment have also been designed to assist the economy. For instance, in the nineteenth century, frontier lands were awarded to veterans, in part as a way to promote the frontier regions of the country. During the Depression, $\$ 3.5$ million in adjusted benefits were awarded to World War I veterans, and this was seen as a way of stimulating the weakened economy. The G.I. Bill of 1944 was viewed not only as a reward to soldiers for military service but also as a mechanism for supporting the American educational system and the economy. According to olson (1974), educational and financial benefits were enacted due to the fear that the reentry of veterans in great numbers into a shaky economy after the war would create massive unemployment and consequently dangerous political instability. The resulting advantage to individual veterans may be seen in the fact that their median income in 1977 was $\$ 4500$ higher than that of non-veterans. The average educational attainment of veterans is higher than that of nonveterans, and at each educational level veterans have higher incomes (Cleland, 1979). Preference given to veterans in civil service hiring has certainly contributed to this advantageous position.

The building of V.A. medical facilities constitutes an important investment in a community and therefore may also be used as an economic tool. A recent decision to build a new V.A. hospital in Canden, N. J. despite the existence of facilities in nearby Philadelphia, resulted from persistent political pressure on President Carter, who reversed his opposition to the plan. Camden's mayor described the project as "the cornerstone of a rebuilding program intended to restore the city's economic viability." The hospital was expected to generate 1000 jobs directly and many more indirectly because of the growth of doctors' offices, restaurants, bank branches, and other business (New York Times, Feb. 22, 1978).

The V.A. system has also contributed to the economic well-being of professional interests. Medical schools, for instance, have found V.A. hospitals to be a useful source of "teaching material," research funds, and additional teaching staff (Sapolsky, 1977). In 1978, the V.A. had 2000 arrangements with schools teaching health professionals, and more than 97,000 students received training in V.A. facilities (Cleland, 1979). The Camden V.A. Hospital, for instance, was planned in conjunction with the expansion of a private medical center to include training of medical students. 
4) Organized Medical Interests

Despite these economic and teaching advantages, one would expect organized medical interests to oppose the expansion of V.A. services. The AMA, for instance, has waged a battle against statefunded or administered medical care for decades (Burrow, 1963; Marmor, 1970; Stevens, 1971). Yet the V.A. has received considerable assistance and support from the AMA and from prominent medical educators. Since 1924, advisory groups of physicians from a broad range of specialty areas have been formed to assist the veterans' medical system. The first of these, the Medical Council, was chaired by Dr. Ray Lyman Wilbur, at that time President of Stanford University and also President of the AMA. The Secretary was Dr. Malcolm MacEachern, Associate Director of the American College of Surgeons, and the other officers were medical school professors. The Council endorsed the establishment of relations between V.A. hospitals and medical schools and the carrying out of medical research by the V.A.

Formal affiliation with medical schools was authorized in 1946 , and it has been seen as a major factor in upgrading the quality of v.A. medical care (National Academy of Sciences, 1977: 253). This relationship has been applauded both by the American Association of Medical Colleges and the editors of the Journal of Medical Education (JME, 1977). Adkins concluded that the "V.A. has the cooperation of organized medicine and an excellent reputation" (1967: 220).

The alliance with medical schools, however, has also been strongly criticized. It has resulted, according to some scholars, in the abandonment of the needs of the V.A.'s primary clientele-the chronically disabled, both physically and mentally--for the attractions of acute tertiary care and teaching (Lipsky, et a1, 1976; Sapolsky, 1977).

Despite this history of cooperation, organized medical interests did oppose some facets of V.A. expansion, in particular, the inclusion of non-service connected veterans. The provision of general medical care for these patients more clearly intruded into the domain of private medicine. During the post-World War II period of V.A. reorganization, the AMA House of Delegates passed a resolution expressing its "long-established opposition to any attempt at the socialization of medicine in America by extending medical benefits under the Veterans Administration to encompass disabilities that are not service-connected or to general medical care of the dependents of veterans" (Starr, 1973: 75). Starr concludes that this ongoing opposition significantly slowed the development of V.A. health services and that the more recent extension of benefits (outpatient care for non-service connected veterans and services for some dependents) may be attributed to a decline in AMA power. 
5) Ideological Component

The history of social welfare is permeated by repeated attempts to separate the "deserving" from the "undeserving" and to provide benefits only for the former. Legislators as well as private agencies have sought to make assistance available only to those whom they have determined not to be personally at fault for their misfortune, particularly children, the elderly, the disabled, and widows. Ablebodied men have rarely received aid because, except in cases of severe national depression or disruption, they have been assumed to be responsible for their own suffering. This idea of individual responsibility is a strong ideological component of capitalism and a persistent theme in public opinion and in social policy (Rimlinger, 1971; Feagin, 1975; Galper, 1975). Its consequence is the limitation of assistance only to those who demonstrate exceptional circumstances or merit.

The veteran, and especially the disabled veteran, is an excellent example of this principle. He (and in $98 \%$ of cases the veteran is a male) has been treated not only as the victim of exceptional circumstances but is doubly deserving for having served the country in battle. He has therefore "earned" the right to a variety of benefits, including education, employment advantages, and medical care.

Robinson Adkins, a V.A. official and the author of a history of veterans' medical care, wrote, "The American people, acting through Congress, have supported the principle that a man who devotes part of his life--usually his young manhood--to defend his country, should be offered advantages over those who do not" (1967:4). The principle of rewarding those who have served in the military is a very old one. In ancient Rome, muncipal offices were often awarded to veterans and their descendants. Throughout the kiddle Ages, various forms of cash relief and institutional care were provided for veterans. During the nineteenth century in the United States, veterans received free land as well as pension benefits. In 1917, when Secretary of the Treasury McAdoo transmitted to President Wilson legislation expanding veterans' benefits, he wrote, "Every man should know that the moment he is enlisted in the military service of the Government these definite guarantees and assurances are given to him, not as charity but as part of his deserved compensation for the extra hazardous occupation into which the Government has forced him" (Adkins, 1967: 94). Most recently, in response to proposals that the V.A. medical system be phased out, an economist commented that this would deprive many needy veterans--the elderly, poor, and chronically ill--of access to medical care (Ginzberg, 1978). The underlying assumption appears to be that these categories of people are more entitled to such care if they are veterans.

The provision of services to veterans is thus based on the notion that they have deserved it. The distinction according to merit is also found even within the veteran population. The most basic differentiation among veterans is between those with service-connected 
disabilities and those who were not disabled as a result of military service. This distinction has governed pension and compensation benefits since these were first voted in the U.S. in 1776 for disabled Revolutionary War soldiers. Although eligibility for medical care has been constantly redefined to include more veterans and more kinds of services, service-connected disability has remained the principle guarantee of care. Since 1924 financial need has also been considered a basis for hospital care if beds are available. Outpatient care, available originally only for service-connected disabilities, was extended in 1973 to veterans without disabilities if they are eligible for hospitalization and if such care is related to or would prevent hospitalization. Disabled veterans are subject to the same limitations if they seek outpatient treatment for a condition not related to their disability. Veterans without service-connected disabilities may also be hospitalized if they are 65 or older or if they are Medal of Honor winners. An honorable discharge and at least one day of active duty are prerequisites for any health care (National Academy of Sciences, 1977).

The eligibility criteria which must be met by applicants for V.A. medical care are increasingly complex. Each time that Congress enacts new medical benefits, it sets restrictions on categories of veterans who are eligible for them, and a priority ranking establishing who should be admitted first in case of insufficient facilities. For instance, dental benefits were extended in 1979 to veterans of the two World Wars and Korea, the totally disabled, and Vietnam veterans who had been prisoners of war for more than six months. At the same time, World War I veterans were accorded top priority ranking for access to outpatient medical services (Wehr, 1979c, 1979d).

Each year, approximately $20 \%$ of all applications for medical services are rejected as ineligible or not in need of care (Cleland, $1977,1978,1979)$. Only $10-13 \%$ of veterans use V.A. health services, suggesting that the large majority never apply. The priority system was created by Congress specifically to limit access to V.A. health care, and it certainly is one important factor in reducing utilization. Many veterans do not use V.A. facilities either because they are ineligible or because they mistakenly think they are. In a recent survey of rural veterans, the failure to use V.A. medical care was often explained as resulting from uncertainty about eligibility. The essential point is that eligibility, not need, governs access to V.A. system. This principle is characteristic of other health and welfare services.

\section{Impact on Distribution}

The limitation of governmentally-run services to "deserving" groups, the importance of political and economic forces in determining where facilities will be built, and the use of health services to promote military aims, all have the effect of exacerbating inequities in the U.S. medical care system. In particular, rural residents and 
women are at a disadvantage, the former because of inaccessibility of services, the latter because of eligibility requirements. Whenever medical resources are allocated by the state for purposes other than the alleviation of suffering and on bases other than need, the result is inequality in the availability of services to potential patients.

The distribution of 172 hospitals in a country the size of the United States inevitably leads to difficulties of access for many eligible veterans. Since distance is generally related to the use of medical services (Shannon et al, 1969), it is not surprising that rural veterans are much less likely to take advantage of their medical eligibility. A study of the use of services by veterans living on Cape Cod, for example, showed that the hour and half to three hours traveling time to a V.A. hospital inhibited its utilization. A review of outpatient records at the Providence V.A. Hospital, which serves Cape Cod as part of its region, revealed that only $1.1 \%$ of visits between March 1 and June 30, 1976 were by veterans from the Cape. Yet the veteran population on Cape Cod constitutes $8 \%$ of the veterans in the Providence region. A survey of veterans on Cape Cod revealed an almost total lack of use of V.A. medical facilities (Wessen et al, 1976). In a recent survey of 200 men in three rural counties in Central Pennsylvania, a similar failure to use any V.A. services was found.

Medical services for veterans, as with social and health services generally, begin and expand or contract in response to the organized political activity of client groups, legislators, the military, and those provider groups who might either benefit or suffer from greater involvement of the state. Consequent1y, services are often ma1distributed or inappropriate. The location of hospitals has been decided on the basis of prestige needs of powerful leaders or lobbying abilities of local communities and their representatives rather than on an assessment of need. (The V.A. has so far been exempt from the certificate of need regulations governing private medical facilities).

\section{v. Conclusion}

Navarro writes that the American health care system reflects the class structure of U.S. society in its organization and in the decision-making process. Veterans' benefits, medical care being a major portion, may be analyzed similarly. They are neither an anomaly nor an anachronism. They directly respond to the economic, military and political priorities of powerful groups in the society. The fact that V.A. health services are federally financed and organized, not unlike the health systems of Eastern Europe, hardly means that socialism is rampant in the American government. It suggests rather that military goals are central to the society and, 
that, as a result, veterans are a powerful lobby and have the support of much of the population in their efforts to expand "well-earned" benefits. The V.A. system dramatically supports the dominant American value that services are a privilege to be earned and not a right of citizenship. This is certainly not a socialist approach. In addition, the care of aging, poor, and chronically disabled soldiers is generally uninteresting and unprofitable for the acute-care oriented practitioners who dominate private medicine, and they have not sought to take on this responsibility.

A national health system modeled on the V.A. may reflect the same principles and produce the same results. This would particularly be the case if national health care eoexists with the private system, the former covering only special categories of people and those who are uninteresting to or cannot afford private medical care. Competition between the two systems for money and personnel has created some disadvantages for the V.A., since the resources of private medicine are so much greater (Starr, 1973). Continued coexistence of the two systems will perpetuate the weaknesses of the public services, as has already been seen in cities where public and private hospitals exist side by side (Kotelchuck, 1976).

The V.A. medical system has often benefited from the interests discussed here, but it is also vulnerable because of them. Unfavorable public reactions to the Vietnam War have diminished the "deserving" aura around its veterans, and thus weakened popular comitment to veterans' services. The reduction in numbers of veterans in Congress and the "deep generational divisions" between veterans of Vietnam and of earlier wars over the form that benefits should take (Wehr, 1979a) have resulted in attenuated political influence. In addition, budgetary concerns have led members of Congress to challenge the expenditure of funds for veterans as being too costly (Wehr, 1979b).

Certainly the V.A. medical system has provided much-needed care for millions of people. However, a study of the V.A. provides further evidence that societal resources are not distributed in response to universalistic principles of medical necessity (nor of economic efficiency). The predominance of other goals may present problems for many veterans (e.g. those in rural areas) as well as for non-veterans, who are excluded from this potentially important source of medical care. 


\section{References}

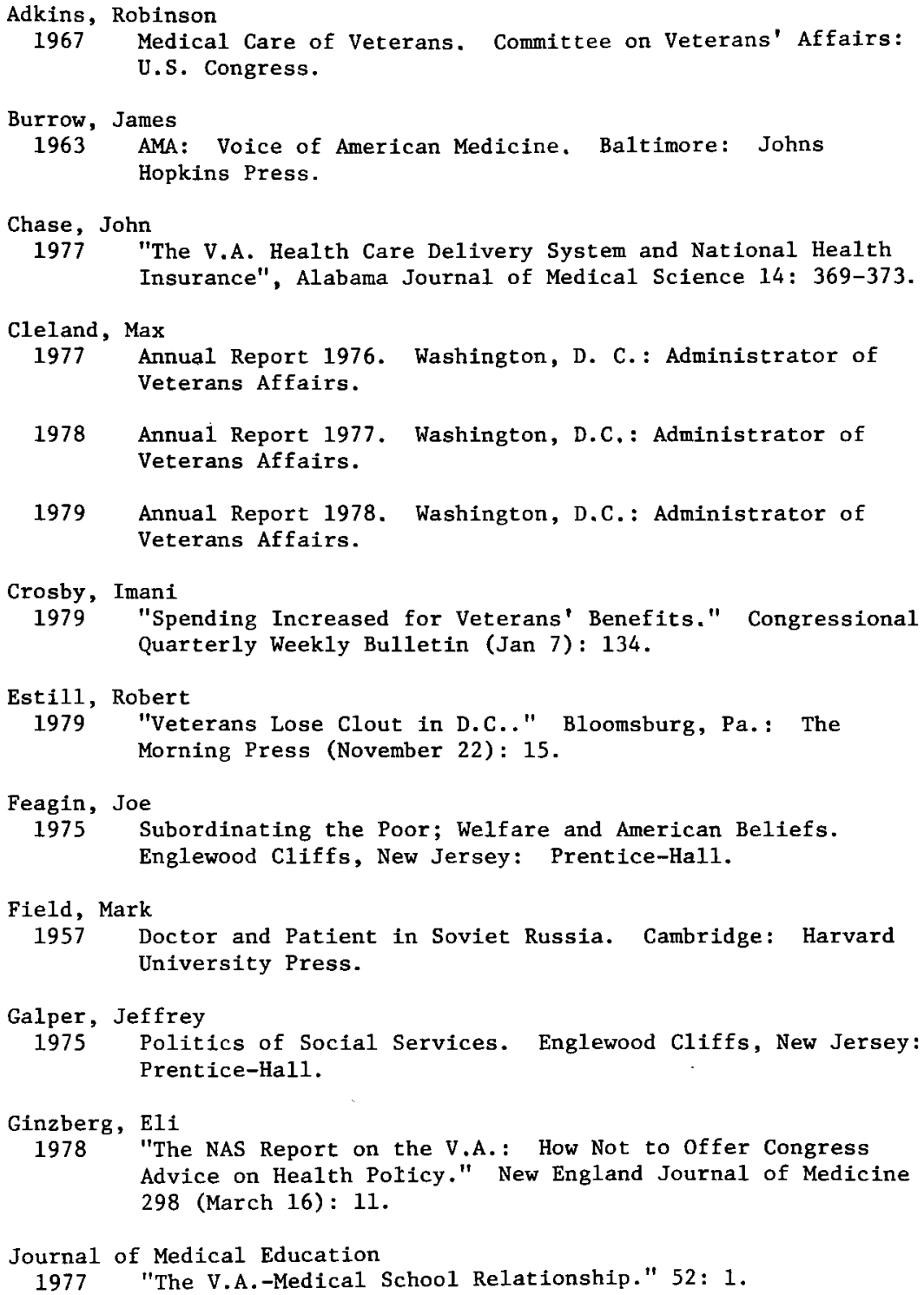


Kotelchuck, David

1976 Prognosis Negative; Crisis in the Health Care System. New York: Vintage.

Krause, El1iot

1977 Power and Illness; The Political Sociology of Health and Medical Care. New York: Elsevier.

Lasker, Judith

1977 "The Role of Health Services in Colonial Rule." Culture, Medicine, and Psychiatry 1: 277-297.

Lindsay, Cotton

1975 Veterans Administration Hospitals; An Economic Analysis of Government Enterprise. Washington, D. C.: American Enterprise Institute for Economic Research.

Lipsky, Michael, Lawrence McCray, Jeffrey Prottas, and Harvey Sapolsky 1976 "The Future of the Veterans' Health Care System." Journal of Health, Politics, Policy, and Law 1 (Fa11): 285-294.

Marmor, Theodore

1970 The Politics of Medicare. Chicago: Aldine.

National Academy of Sciences

1977 Study of Health Care of American Veterans. Washington, D. C.

Navarro, Vicente

1976 Medicine under Capitalism. New York: Prodist

1977a "Social Class, Political Power and the State and their Implications in Medicine", International Journal of Health Services 7: 255-292.

1977b Social Security and Medicine in the USSR. Lexington, Itass: Lexington Books.

New England Journal of Medicine

1978 "The Future of the Veterans Administration Hospital System: Two Points of View," 298 (March 16): 11.

New York Times

1978 February 22: 51. (New Jersey).

0lson, Keith

1974 The G.I. Bill, The Veterans, and the Colleges. Lexington: University Press of Kentucky.

Piven, Frances Fox, and Richard Cloward

1971 Regulating the Poor: The Functions of Public Welfare. New York: Pantheon. 


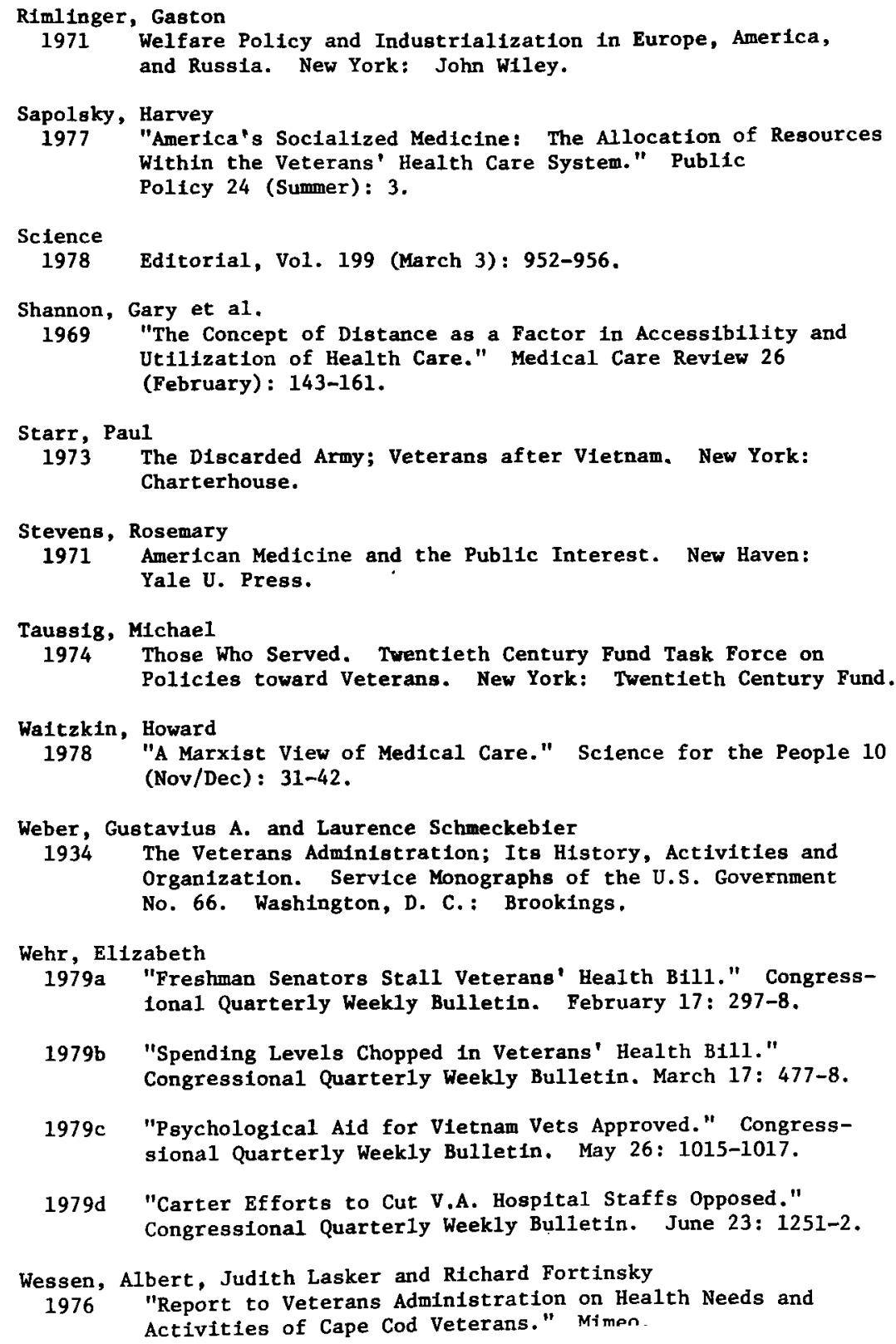

